\title{
Eğirdir Gölü ve Çevresindeki Kaynak Sularından Alınan Su Örneklerinde Organik Klorlu Pestisit, Polibromlu Difenil Eter ve Poliklorlu Bifenil Bileşiklerinin Belirlenmesi
}

\author{
Ulaş ACARÖZ $^{1 *}$, Özgür KUZUKIRAN², Serkan KARATEKELİ ${ }^{1}$, \\ Sinan INCE ${ }^{3}$, Ayhan FÍLAZI ${ }^{4}$

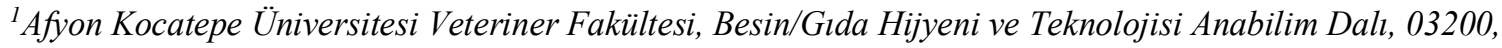 \\ Afyonkarahisar, Türkiye \\ ${ }^{2}$ Çankırı Üniversitesi, Eldivan Sağllk Hizmetleri Meslek Yüksekokulu, Laborant ve Veteriner Sağllk Programı, \\ 18700, Çankir, Türkiye \\ ${ }^{3}$ Afyon Kocatepe Üniversitesi Veteriner Fakültesi, Farmakoloji ve Toksikoloji Anabilim Dall, 03200, \\ Afyonkarahisar, Türkiye \\ ${ }^{4}$ Ankara Üniversitesi Veteriner Fakültesi, Farmakoloji ve Toksikoloji Anabilim Dall, 06110, Ankara, Türkiye \\ (ORCID: 0000-0002-1533-4519) (ORCID: 0000-0001-9294-2801) (ORCID: 0000-0003-2491-7350)
}

(ORCID: 0000-0002-1915-9797) (ORCID: 0000-0002-2800-6215)

\begin{abstract}
$\ddot{O} z$
Kalıcılığı en çok gözlenen organik bileşikler, organik klorlu pestisitler, polibromlu difenil eter ve poliklorlu bifeniller olup bunların insan, hayvan ve çevre sağlığına olumsuz etkileri söz konusu olmaktadır. Eğirdir gölü Akdeniz bölgesinde Isparta ili sınırları içerisinde Sultan ve Karakuş Dağları'nın arasında yer alan Türkiye'nin dördüncü büyük gölüdür. Bu gölde balık yetiştiriciliği yapılmaktadır. Bu nedenle, bu gölün kirleticiler açısından kontamine olmaması halk sağlığı ve ekonomik açıdan önem arz etmektedir. Bu çalışmada Ocak 2018 ile Aralık 2018 tarihleri arasında 48 noktadan toplanan 192 su örneğinde 9 organik klorlu pestisit ( $\alpha$-hekzaklorosiklohekzan, $\beta$-hekzaklorosiklohekzan, $\gamma$-hekzaklorosiklohekzan, hekzaklorobenzen, 4,4'-diklorodifenil dikloroetan, 4,4'diklorodifenil dikloroetilen, 2,4'-diklorodifenil trikloroetan, 4,4'-diklorodifenil trikloroetan, ve heptaklor), 7 poliklorlu bifeniller $(28,52,101,118,138,153,180)$ ve 6 polibromlu difenil eterler $(17,47,66,100,153,183)$ olmak üzere toplam 22 organik bileşiğin varlığı GC-MS cihazı ile araştırıldı. Yapılan çalışmada Eğirdir Gölü'nden ve çevresindeki kaynak sularından alınan su örneklerinin hiçbirinde ölçüm limitlerinin üzerinde kalıcı organik varlı̆̆ına rastlanmadı. Bu durum, Eğirdir gölünün ve çevresindeki kaynak sularının organik kirleticiler yönünden temiz olduğunu göstermektedir.
\end{abstract}

Anahtar kelimeler: Organik klorlu pestisitler, polibromlu difenil eter, poliklorlu bifeniller, Eğirdir Gölü.

\section{Determination of Organic Chlorinated Pesticide, Polybrominated Diphenyl Ethers and Polychlorinated Biphenyl Compounds in Water Samples from Eğirdir Lake and Surrounding Spring Waters}

\begin{abstract}
The most common persistent organic compounds are organic chlorinated pesticides, polybrominated diphenyl ethers and polychlorinated biphenyls, which have adverse effects on human, animal and environmental health. Eğirdir lake is fourth-largest lake of Turkey that is located in the Mediterranean area between Sultan and Karakus mountains in the province of Isparta. Fish farming are performed in this lake. Therefore, it is important for public health and economic reasons that this lake is not contaminated by pollutants. In this study, 192 water samples which were collected from 48 points between January 2018 and December 2018 were investigated regarding the presence of a total of 22 organic compounds including 9 organic chlorinated pesticides ( $\alpha$-hexachlorocyclohexane, $\beta$-hexachlorocyclohexane, $\gamma$-hexachlorocyclohexane, hexachlorobenzene, 4,4'-dichlorodiphenyldichloroethane, 4,4'-dichloro diphenyldichloroethylene, 2,4'-dichlorodiphenyltrichloroethane, 4,4'dichlorodiphenyltrichloroethane, and heptachlor), 7 polychlorinated biphenyls $(28,52,101,118,138,153,180)$
\end{abstract}

*Sorumlu yazar: ulasacaroz@aku.edu.tr

Geliş Tarihi: 16.01.2020, Kabul Tarihi: 04.02.2020 
and 6 polybrominated diphenyl ethers $(17,47,66,100,153,183)$ by means of GC-MS. In the study, it was determined that none of the water samples taken from Eğirdir Lake and the surrounding spring waters contained persistent organic compounds above the measurement limits. This shows that Eğirdir Lake and surrounding spring waters are clean for organic pollutants.

Keywords: Organic chlorinated pesticides, polybrominated diphenyl ethers, polychlorinated biphenyls, Eğirdir Lake.

\section{Giriş}

Poliklorlu bifeniller ve organik klorlu bileşikler gibi kalıcı organik kirleticiler, bozulmaya karşı dirençleri ile ekosistemlere ve insan refahına zararlı etkileri ile karakterize edilen bir grup sentetik bileşikten oluşmaktadır [1]. Poliklorlu bifeniller yaygın olarak yalıtkan, ssıya dayanıklı sıvılar, makine yağları, plastikler, boyalar, alev geciktiriciler ve yapıştırıların yapısında yaygın olarak kullanılmıştır. Aynı şekilde, organik klorlu bileşikler diklorodifeniltrikloroetan, diklorodifenildikloroetan, diklorodifenildikloroetilen geçmişte tarımsal ürünlerdeki böcekleri ve böcek kaynaklı hastalıkları kontrol etmek için yaygın olarak kullanılmıştır [2]. Diğer pestisitler, hekzaklorobenzen, hekzaklorosikloheksan, heptaklor, aldrin, dieldrin ve endrin gibi bileşiklerde tarımda yaygın bir şekilde böcek ilacı olarak kullanımı tercih edilmiştir. Bu maddeler biyolojik ve kimyasal bozulmaya karşı oldukça dirençli olup hidrofobik özellikleri nedeniyle sudaki organizmaların lipit açısından zengin dokularında, suda ve sedimentlerde partikül madde olarak bulunurlar. Bunların, birikici özelliklerinden dolayı diğer su canlılarında da birikmesi ve besin zincirinde artan miktarlarda bulunması söz konusu olmaktadır. Toksik özellikleri nedeniyle, organik klorlu bileşiklere maruz kalmak insan sağlığı ve çevre üzerinde zararlı etkilere neden olduğu için üretimi ve kullanımı yasaklanmıştır [3,4]. Buna karşın bu maddelerin yasal olmayan yollardan kullanımları veya bunların uzun süre bozulmadan kalmaları sonucunda ortamdaki varlıkları nadiren de olsa görülebilmektedir.

$\mathrm{Su}$, dünya çapında yaşamın sürdürülebilirliği için doğal kaynaklar arasında en önemlisi olarak kabul edilmektedir [5]. Ancak tatlı sular doğrudan insan faaliyetleri tarafından tehdit edilmektedir. Hızlı sanayileşme, bitkisel üretim için haşere ve hastalık kontrolünde kullanılmaları ile yiyecek ağı veya içme suyu kaynakları yoluyla doğal ve sucul yaşam ile halk sağlığına ciddi zararlar verdiği bulunmuştur [6,7].

Türkiye'nin dördüncü büyük gölü olan Eğirdir Gölü Akdeniz bölgesinde Isparta ili sinırları içerisinde Sultan ve Karakuş Dağları'nın arasında yer almaktadır. Balık yetiştiriciliği ve kerevit avlanması yanında tarım arazilerine de su kaynağı sağlayan bu göl bölgesel ekosistem açısından önem arz etmektedir. Bu çalışmada gölden alınan su örneklerinde olası kalıcı organik bileşiklerin (klorlu pestisitler, polibromlu difenil eterler ve poliklorlu bifeniller) konsantrasyonlarının mevsimsel olarak tespit edilmesi amaçlanmıştır.

\section{Materyal ve Metot}

\section{1. Örnekler}

Bu çalışma kapsamında Eğirdir Gölü ve çevresindeki kaynak sularından Ocak 2018 ile Aralık 2018 tarihleri arasında mevsimsel olarak 192 su örneği toplandı. (Şekil 1). Bu örnekler üçer aylık periyotlarda birer adet numune olacak şeklinde 48 faklı noktadan (11 çeşme ve 37 göl noktası) toplandı. Su örnekleri VB soğuk zincir altında laboratuvara getirildi ve analiz edilinceye kadar $-20{ }^{\circ} \mathrm{C}$ 'de saklandı. $\mathrm{Su}$ örneklerinin alındığı noktaların koordinatları tablo 1'de gösterildi.

\subsection{Kimyasallar}

Analitik saflıkta olacak şekilde seçilen kimyasallar n-hekzan, izooktan, asetonitril, metanol ve diklorometan Sigma Aldrich (Steinheim, Almanya), C18 toz olarak Agilent Technologies (Santa Clara, Birleşik Devletler) 'den alındı.

Analitik poliklorlu bifenil (PCB) standartlar1 (PCB28, PCB30, PCB52, PCB101, PCB118, PCB138, PCB153 ve PCB180) ve Organik Klorlu Pestisit standartlar1 [ $\alpha$-hekzaklorosiklohekzan $(\alpha-$ $\mathrm{HCH}), \quad \beta$-hekzaklorosiklohekzan $(\beta-\mathrm{HCH}), \gamma$-hekzaklorosiklohekzan $(\gamma-\mathrm{HCH})$, hekzaklorobenzen 
(HCB), 4,4'-diklorodifenil dikloroetan (4,4'-DDD), 4,4'-diklorodifenil dikloroetilen (4,4'-DDE), 2,4'diklorodifenil trikloroetan (2,4'-DDT), 4,4'-diklorodifenil trikloroetan (4,4'-DDT) ve heptaklor (HEP)] Dr. Ehrenstorfer Laboratories (Augsburg, Almanya), polibromlu difenil eter (PBDE) standartlar1 (PBDE17, PBDE47, PBDE66, PBDE100, PBDE153, PBDE183) Wellington Laboratories (Guelph, Kanada), izotop işaretli PCB153 (13C12) Cambridge Isotope Laboratories (Andover, MA, Birleşik Devletler)' den alındı. İzotop işaretli PCB153 (13C12) internal standart, PCB30 ise enjeksiyon internal standardı olarak kullanıldı. Stok standart solüsyonları asetonitril içinde $100 \mathrm{ng} / \mathrm{mL}$ olacak şekilde hazırland 1 ve $-20^{\circ} \mathrm{C}$ 'de saklandi.

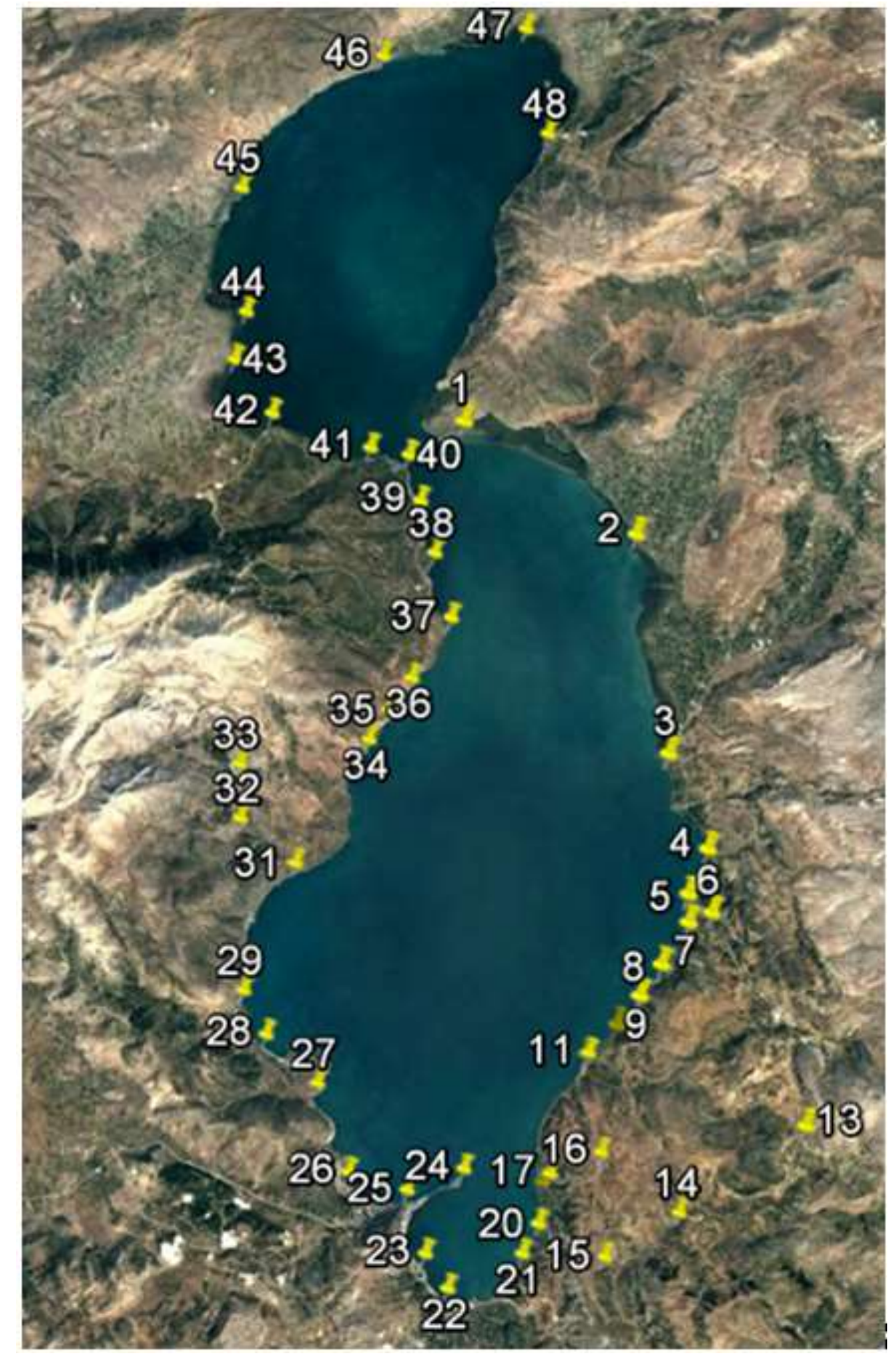

Şekil 1. Eğirdir gölünden alınan örnekleme yapılan yerlerin görüntüsü [8] 
Tablo 1. Su örneklerinin alındıkları yerler ve koordinat bilgileri

\begin{tabular}{|c|c|c|c|}
\hline Sira & Adı (Yerel olarak isimlendirilen noktalar) & Enlem & Boylam \\
\hline 1- & Göl Karabağlar & $37^{\circ} 52^{\prime} 49.05^{\prime \prime K}$ & $30^{\circ} 54^{\prime} 12.91^{\prime \prime} \mathrm{D}$ \\
\hline 2- & Göl Karabulak & $37^{\circ} 51^{\prime} 57.52^{\prime \prime} \mathrm{K}$ & $30^{\circ} 54^{\prime} 10.22^{\prime \prime} \mathrm{D}$ \\
\hline 3- & Göl Göktaş & $37^{\circ} 51^{\prime} 19.68^{\prime \prime} \mathrm{K}$ & $30^{\circ} 53^{\prime} 47.28^{\prime \prime} \mathrm{D}$ \\
\hline 4- & Göl Köprübaşı & $37^{\circ} 50^{\prime} 32.85^{\prime \prime K}$ & $30^{\circ} 51^{\prime} 54.27^{\prime \prime} \mathrm{D}$ \\
\hline 5- & Göl Kervansaray & $37^{\circ} 51^{\prime} 14.56^{\prime \prime K}$ & $30^{\circ} 51^{\prime} 17.18^{\prime \prime} \mathrm{D}$ \\
\hline 6- & Göl Yeşilada & $37^{\circ} 53^{\prime} 1.41 " \mathrm{~K}$ & $30^{\circ} 52^{\prime} 11.21^{\prime \prime D}$ \\
\hline 7- & Göl İlçe Tarım & $37^{\circ} 52^{\prime} 32.21^{\prime \prime K}$ & $30^{\circ} 50^{\prime} 44.96^{\prime \prime} \mathrm{D}$ \\
\hline 8- & Göl Altınkum & $37^{\circ} 52^{\prime} 50.83^{\prime \prime} \mathrm{K}$ & $30^{\circ} 49^{\prime} 12.26^{\prime \prime} \mathrm{D}$ \\
\hline 9- & Göl Askeriye & $37^{\circ} 54^{\prime} 38.58^{\prime \prime} \mathrm{K}$ & $30^{\circ} 48^{\prime} 19.04^{\prime \prime} \mathrm{D}$ \\
\hline 10- & Göl Beydere Plajı & $37^{\circ} 55^{\prime} 35.87^{\prime \prime} \mathrm{K}$ & $30^{\circ} 46^{\prime} 56.04^{\prime \prime} \mathrm{D}$ \\
\hline 11- & Göl DSİ Plaj & $37^{\circ} 56^{\prime} 28.85^{\prime \prime} \mathrm{K}$ & $30^{\circ} 46^{\prime} 18.05^{\prime \prime} \mathrm{D}$ \\
\hline 12- & Göl PTT Plaj & $37^{\circ} 57^{\prime} 8.69^{\prime \prime} \mathrm{K}$ & $30^{\circ} 46^{\prime} 22.05^{\prime \prime D}$ \\
\hline 13- & Göl Bağören Kooperatif & $37^{\circ} 59^{\prime} 8.41^{\prime \prime K}$ & $30^{\circ} 47^{\prime} 29.79^{\prime \prime} \mathrm{D}$ \\
\hline 14- & Göl Sariidris Liman & $37^{\circ} 58^{\prime} 13.40^{\prime \prime} \mathrm{K}$ & $30^{\circ} 57^{\prime} 41.37^{\prime \prime D}$ \\
\hline 15- & Göl Sarıidris Petrol & $37^{\circ} 57^{\prime} 20.26 " \mathrm{~K}$ & $30^{\circ} 57^{\prime} 2.79^{\prime \prime} \mathrm{D}$ \\
\hline 16- & Göl Mahmatlar Çıkış & $37^{\circ} 56^{\prime} 40.52 " \mathrm{~K}$ & $30^{\circ} 56^{\prime} 30.87^{\prime \prime} \mathrm{D}$ \\
\hline 17- & Göl Pazaryeri Mahmatlar & $37^{\circ} 55^{\prime} 29.54^{\prime \prime} \mathrm{K}$ & $30^{\circ} 55^{\prime} 10.91^{\prime \prime} \mathrm{D}$ \\
\hline 18- & Göl Çorak & $38^{\circ} 3 ' 2.83 " \mathrm{~K}$ & $30^{\circ} 50^{\prime} 17.45^{\prime \prime} \mathrm{D}$ \\
\hline $19-$ & Göl Boyalı Mezaraltı & $38^{\circ} 2^{\prime} 22.10^{\prime \prime} \mathrm{K}$ & $30^{\circ} 49^{\prime} 44.71^{\prime \prime} \mathrm{D}$ \\
\hline 20- & Göl Boyalı B.Güngör & $38^{\circ} 1^{\prime} 44.78^{\prime \prime K}$ & $30^{\circ} 49^{\prime} 15.56^{\prime \prime} \mathrm{D}$ \\
\hline 21- & Göl Boyalı Çevikçelik & $38^{\circ} 4^{\prime} 19.15^{\prime \prime K}$ & $30^{\circ} 51^{\prime} 14.18^{\prime \prime} \mathrm{D}$ \\
\hline 22- & Göl Boyalı Kocakurt & $38^{\circ} 5^{\prime} 37.95 " \mathrm{~K}$ & $30^{\circ} 50^{\prime} 44.43^{\prime \prime} \mathrm{D}$ \\
\hline 23- & Göl Boyalı Ekobir Kamp & $38^{\circ} 6^{\prime} 41.50^{\prime \prime K}$ & $30^{\circ} 50^{\prime} 18.41^{\prime \prime} \mathrm{D}$ \\
\hline 24- & Göl Bağcıyaz İlerisi & $38^{\circ} 7^{\prime} 37.13^{\prime \prime K}$ & $30^{\circ} 49^{\prime} 57.50^{\prime \prime} \mathrm{D}$ \\
\hline 25- & Göl Büyükkabaca & $38^{\circ} 10^{\prime} 24.68^{\prime \prime K}$ & $30^{\circ} 45^{\prime} 34.42^{\prime \prime} \mathrm{D}$ \\
\hline 26- & Göl Gençali & $38^{\circ} 12^{\prime} 32.45^{\prime \prime} \mathrm{K}$ & $30^{\circ} 45^{\prime} 8.99^{\prime \prime} \mathrm{D}$ \\
\hline 27- & Göl Taşevi & $38^{\circ} 16^{\prime} 10.03^{\prime \prime K}$ & $30^{\circ} 50^{\prime} 0.52^{\prime \prime} \mathrm{D}$ \\
\hline 28- & Göl Aşağıkaşıkara & $38^{\circ} 16^{\prime} 28.04^{\prime \prime K}$ & $30^{\circ} 52^{\prime} 29.59^{\prime \prime} \mathrm{D}$ \\
\hline 29- & Göl Tirtar & $38^{\circ} 14^{\prime} 43.25^{\prime \prime} \mathrm{K}$ & $30^{\circ} 53^{\prime} 26.61^{\prime \prime D}$ \\
\hline 30- & Göl Akkeçili & $38^{\circ} 7^{\prime} 43.98^{\prime \prime K}$ & $30^{\circ} 48^{\prime} 57.16^{\prime \prime} \mathrm{D}$ \\
\hline 31- & Göl Kayaağzı & $38^{\circ} 8^{\prime} 21.13^{\prime \prime K}$ & $30^{\circ} 46^{\prime} 22.13^{\prime \prime} \mathrm{D}$ \\
\hline 32- & Göl Sarnidris & $37^{\circ} 58^{\prime} 48.34^{\prime \prime K}$ & $30^{\circ} 57^{\prime} 39.18^{\prime \prime D}$ \\
\hline 33- & Göl Yeşilköy & $37^{\circ} 59^{\prime} 44.72^{\prime \prime} \mathrm{K}$ & $30^{\circ} 58^{\prime} 6.67^{\prime \prime} \mathrm{D}$ \\
\hline 34- & Göl Hacılar & $38^{\circ} 1 ' 39.93 " \mathrm{~K}$ & $30^{\circ} 56^{\prime} 59.69^{\prime \prime} \mathrm{D}$ \\
\hline 35- & Göl Avşar & $38^{\circ} 6^{\prime} 8.13^{\prime \prime} \mathrm{K}$ & $30^{\circ} 55^{\prime} 54.65^{\prime \prime} \mathrm{D}$ \\
\hline 36- & Göl Yenice & $38^{\circ} 8^{\prime} 18.24^{\prime \prime K}$ & $30^{\circ} 51^{\prime} 19.82^{\prime \prime} \mathrm{D}$ \\
\hline 37- & Göl Garip & $38^{\circ} 9^{\prime} 4.60^{\prime \prime} \mathrm{K}$ & $30^{\circ} 45^{\prime} 9.58^{\prime \prime} \mathrm{D}$ \\
\hline 38- & Çeşme Bağacık & $37^{\circ} 54^{\prime} 9.01^{\prime \prime K}$ & $31^{\circ} 0^{\prime} 56.09^{\prime \prime} \mathrm{D}$ \\
\hline 39- & Çeşme Kıymetli & $37^{\circ} 52^{\prime} 18.76^{\prime \prime} \mathrm{K}$ & $30^{\circ} 57^{\prime} 46.86^{\prime \prime} \mathrm{D}$ \\
\hline 40- & Çeşme Gıymetli Sorkuncak Arası & $37^{\circ} 51^{\prime} 20.34^{\prime \prime K}$ & $30^{\circ} 55^{\prime} 55.10^{\prime \prime} \mathrm{D}$ \\
\hline 41- & Çeşme Sorkuncak & $37^{\circ} 53^{\prime} 29.35^{\prime \prime K}$ & $30^{\circ} 55^{\prime} 42.47^{\prime \prime} \mathrm{D}$ \\
\hline 42- & Çeşme Karabağlar mescit & $37^{\circ} 52^{\prime} 59.96 " \mathrm{~K}$ & $30^{\circ} 54^{\prime} 24.73^{\prime \prime} \mathrm{D}$ \\
\hline 43- & Çeşme Karabulak & $37^{\circ} 51^{\prime} 58.17^{\prime \prime K}$ & $30^{\circ} 54^{\prime} 13.30^{\prime \prime} \mathrm{D}$ \\
\hline 44- & Çeşme Bağören & $38^{\circ} 0^{\prime} 0.80^{\prime \prime} \mathrm{K}$ & $30^{\circ} 46^{\prime} 0.58^{\prime \prime} \mathrm{D}$ \\
\hline 45- & Çeşme Barla Baraj & $38^{\circ} 1^{\prime} 7.51 " \mathrm{~K}$ & $30^{\circ} 45^{\prime} 56.10^{\prime \prime} \mathrm{D}$ \\
\hline 46- & Çeşme Sariidris Yokuş & $37^{\circ} 58^{\prime} 26.38^{\prime \prime K}$ & $30^{\circ} 58^{\prime} 17.00^{\prime \prime} \mathrm{D}$ \\
\hline 47- & Çeşme Söğütlü Mahmatlar & $37^{\circ} 56^{\prime} 3.86^{\prime \prime K}$ & $30^{\circ} 55^{\prime} 57.79^{\prime \prime} \mathrm{D}$ \\
\hline 48- & Çeşme Pazaryeri Mahmatlar & $37^{\circ} 55^{\prime} 30.67^{\prime \prime K}$ & $30^{\circ} 55^{\prime} 16.75^{\prime \prime} \mathrm{D}$ \\
\hline
\end{tabular}

\section{3. Örneklerin analize hazırlanması}

Çalışmada kullanılan yöntem Avrupa Komisyonu Sağlık ve Tüketici Koruma Genel Müdürlügü’nün (SANCO) 12571/2013 sayılı "Gıda ve Yemlerde Pestisit Kalıntılarının Analizi İçin Analitik Kontrol ve Validasyon Prosedürleri Kılavuzu" ve EUROCHEM'in 2014 yılında güncellediği "Yöntem Validasyonu ve İlişkili Konular Kılavuzu"'nda belirtilen kriterlere göre valide edildi [9]. 
Su örnekleri kromatografik analiz için daha önceden bildirilen yönteme göre hazırlandı [10]. Bu amaçla, örnekler 500 mg C18 ile hazırlanan SPE kartuşlar çeker-ocak altında vakum manifoltuna yerleştirilerek $10 \mathrm{ml}$ miktarında sırasıyla n-hexane, diklorometan, metanol ve distile su $5 \mathrm{ml} / \mathrm{dk}$ akış hızında geçirilerek şartlandırmalar sağlandı. Bu işlemi takiben $50 \mathrm{ml}$ su numunesi geçirildi. Vakum altında $30 \mathrm{dk}$ hava geçirilerek kartuşlar tamamen kurutuldu. Ardından 2x5 ml diklorometan:hekzan (1:1, $\mathrm{v} / \mathrm{v})$ geçirilerek analiz için analitler topland 1 ve azot altında $40{ }^{\circ} \mathrm{C}$ 'de uçurma işlemi gerçekleştirildi. Kalıntılar izooktan $(90 \mu 1)$ ile viale toplanarak $10 \mu 1$ injeksiyon internal standard ilave edildi ve GCMS cihazında okutuldu. Geri kazanım çalışmaları 6 tekrarlı olacak şekilde 1, 5 ve $10 \mathrm{ng} / \mathrm{g}$ derişimlerde yapildi.

\subsection{Enstrümantal Analiz}

$\mathrm{Su}$ numunelerinin analizinde Thermo Finnigan Trace GC Polaris Q gaz kromatografi kütle spektrometresi (GC-MS) (San Jose, California, ABD) kullanıldı. Analiz için kullanılan kolon (DB-5MS kapillar kolon, $30 \mathrm{~m} \times 0.25 \mathrm{~mm}$ i.d., $0.25 \mu \mathrm{m}$ film kapl, Agilent Technologies, Palo Alto, CA, Amerika Birleşik Devletleri) splitless modda kullanıldı. Transfer hattı $270^{\circ} \mathrm{C}$, kütle dedektörü $250^{\circ} \mathrm{C}$ ve enjeksiyon bloğu $280{ }^{\circ} \mathrm{C}$ sıcaklığa ayarlandı. Helyum gazı $(\% 99,995)$ mobil faz olarak analitik saflıkta kullanıldı ve bunun akış hızı 1,0 ml/dk olarak ayarlandı.

GC-MS analiz programı için Kuzukiran ve arkadaşları [11] tarafindan çalışılan program kullanıldı. GC-MS firın sıcaklığ 1 başlangıçta $70^{\circ} \mathrm{C}$ 'de $2 \mathrm{dk}$ tutuldu. Daha sonra dk' da $25^{\circ} \mathrm{C}$ artırılarak $150^{\circ} \mathrm{C}^{\prime}$ ye getirildi. Buradan dk'da $5^{\circ} \mathrm{C}$ artırilarak $200^{\circ} \mathrm{C}^{\prime}$ ye getirildi. Burada $5 \mathrm{dk}$ tutulduktan sonra dk'da $5^{\circ} \mathrm{C}$ artarak $270{ }^{\circ} \mathrm{C}$ 'ye getirildi. Ardından hiç beklemeden dakikada $25^{\circ} \mathrm{C}$ artırılarak $290^{\circ} \mathrm{C}$ 'ye getirildi ve $7 \mathrm{dk}$ bekletildi. Toplam program uzunluğ $44 \mathrm{dk}$ olarak hesaplandı. Solvent gecikme zamanı, solvent pikinin atlanması için $11 \mathrm{dk}$ olarak ayarlandı. Kütle taraması için $70 \mathrm{eV}$ enerji uygulanarak 100$800 \mathrm{~m} / \mathrm{z}$ arasındaki iyonlar tarandı. Analitlerin analizi ve doğrulanması bir niceleyici ve 2 niteleyici iyon kullanılarak Seçici İyon Görüntüleme (SIM) moduna göre hesaplandı. İstatistik hesaplamaları "R" paketiyle yapıldı.

\section{Bulgular ve Tartışma}

Su örnekleri için GS/MS ile hesaplanan kalite parametreleri (doğrusallık, LOD, LOQ, Ort. geri kazanım, kesinlik, tekrarlanabilirlik) tablo 2'de gösterilmiştir. Organik klorlu pestisitler için doğrusallık 0,5-10 $\mathrm{ng} / \mathrm{g}$ aralığında belirlenirken, $\mathrm{r}^{2}$ değeri 0,995 ile 0,998 arasında saptandı. LOD değerleri ise 0,182 ile $0,276 \mathrm{ng} / \mathrm{g}$ değerleri arasında bulundu. Poliklorlu bifeniller için ise doğrusallık 0,1-10 ng/g aralığında belirlenirken, $\mathrm{r}^{2}$ değeri 0,996 ile 0,998 arasında saptand. LOD değerleri ise 0,181 ile $0,227 \mathrm{ng} / \mathrm{g}$ değerleri arasında bulundu. Bununla birlikte, polibromlu difenil eterler için doğrusallık $0,1-10 \mathrm{ng} / \mathrm{g}$ aralığında belirlenirken, $\mathrm{r}^{2}$ değeri 0,995 ile 0,998 arasında saptand. LOD değerleri ise 0,124 ile 0,214 $\mathrm{ng} / \mathrm{g}$ değerleri arasında bulundu.

Yapılan analizler neticesinde Eğirdir Gölü ve çevresindeki kaynak sularından mevsimsel olarak 48 farklı noktadan üç aylık periyotlarda toplanan 192 örnekte araştırılan organik klorlu pestisit, polibromlu difenil eter, poliklorlu bifenil varlığına rastlanılmadı.

Daha önce yapılan çalışmalar incelendiğinde; Kuzukıran ve arkadaşları [12] yaptıkları çalışmada 2018 ve 2019 yılları arasında Kızılırmak nehrinden toplanan 60 sediment ve su örneğinde organik klorlu pestisit, poliklorlu bifenil ve polibromlu bifenil kalıntısını araştırmışlar ve en sık tespit edilen bileşiğin 4,4'-DDE olduğu ve en yüksek kalıntının Ağustos ayında tespit edildiğini bildirmişleridir. Yapılan bir diğer çalışmada, Mersin Körfezi'nde organik klorlu pestisit düzeylerinin araştırıldığı bir çalışmada 5 farklı noktadan (Liman, Tisan, Deliburun, Mezitli, Deliçay), 2008-2009 Mart tarihleri arasında mevsimsel değişimi kapsayacak şekilde deniz suyu, yüzey sedimanı ve biyota numuneleri toplanmış ve en yüksek konsantrasyonun Deliburun noktasında olduğu bildirilmiştir. Ayrıca, farklı mevsimlere ait deniz suyu örneklerindeki organik klorlu pestisit konsantrasyonları 0,012 ile $0,031 \mathrm{ppb}$ aralığında olduğu rapor edilmiştir [13].

Bununla birlikte, dünyada bu bileşiklerin kirlilik düzeylerinin araştırıldığı bazı çalışmalar incelendiğinde; Malik ve arkadaşları [14] yılında Hindistan'ın Gomti Nehrinin su ve yataklarındaki kalıcı organik klorlu pestisit kalıntılarının konsantrasyonlarını ve dağılımlarını 2 yıl boyunca mevsimsel olarak toplanan örneklerde incelemişlerdir. Nehir suyunda ve sedimentlerde toplam organik klorlu 
pestisit miktarlarını sırasıyla 2,16-567,49 $\mathrm{ng} / \mathrm{l}$ ve $0,92-813,59 \mathrm{ng} / \mathrm{g}$ arasında tespit etmişlerdir. Sonuç olarak bu kontaminasyonun nehir havzalarına yakın tarımsal alanda bu bileşiklerin kullanılmasından kaynaklandığ belirtilmiştir. Polisiklik aromatik hidrokarbonların, organik klorlu pestisitlerinin ve poliklorlu bifenillerin Çin'deki sularda dağglımı hakkındaki verilerin sunulduğu bir çalışmada, Yangtze nehri, Pearl nehri deltası, Minjiang nehri, Jiulongjiang nehri, Daya koyu, Taihu gölü ve Zhejiang Eyaletinin su kaynaklarında yüksek miktarda bu bileşiklerin bulunduğu ve bu durumun Çin'in güneydoğu kıyıları boyunca, büyük imalat bölgeleri, yoğun tarım havzaları ve diğer sanayi merkezlerinin içinde bulunmasından kaynaklandığı ifade edilmiştir. Çin'in su ortamındaki organik klorlu pestisit seviyelerinin dünyadaki diğer gösterge bölgeleri ile karşılaştırıldığında kirlilik düzeylerinin benzer olduğu ve bu düzeylerin toplam tespit sınırının altından başlayarak en yüksek 5104,8 ng/l seviyesine kadar ulaştığ bildirilmiştir. Buna karşın, kirleticilerden polisiklik aromatik hidrokarbon ve poliklorlu bifenil kirliliğinin Çin'de ciddi seviyelere geldiği de ifade edilmiştir [15].

Tablo 2. Gaz kromatografisi kalite parametreleri

\begin{tabular}{|c|c|c|c|c|c|c|c|}
\hline Analit & $\begin{array}{l}\text { Doğrusallık } \\
\text { (ng/g) }\end{array}$ & $\mathbf{r}^{2}$ & $\begin{array}{l}\text { LOD } \\
\text { (ng/g) }\end{array}$ & $\begin{array}{c}\text { LOQ } \\
\text { (ng/g) }\end{array}$ & $\begin{array}{c}\text { Ort. Geri } \\
\text { kazanım } \\
(\%)\end{array}$ & $\begin{array}{l}\text { Kesinlik } \\
\text { (RSD \%) }\end{array}$ & $\begin{array}{c}\text { Tekrarlanabilirlik } \\
\text { (RSD \%) }\end{array}$ \\
\hline \multicolumn{8}{|c|}{$\begin{array}{l}\text { Organik Klorlu } \\
\text { Pestisitler }\end{array}$} \\
\hline$\alpha-\mathrm{HCH}$ & $0,5-10$ & 0,995 & 0,182 & 0,546 & $94,3 \pm 2,8$ & 6,46 & 6,25 \\
\hline$\beta-Н С Н$ & $0,5-10$ & 0,995 & 0,249 & 0,747 & $95,7 \pm 3,4$ & 8,17 & 7,66 \\
\hline$\gamma-\mathrm{HCH}$ & $0,5-10$ & 0,994 & 0,276 & 0,828 & $95,2 \pm 3,2$ & 10,17 & 9,54 \\
\hline HCB & $0,5-10$ & 0,997 & 0,167 & 0,501 & $93,8 \pm 2,5$ & 7,51 & 7,22 \\
\hline 4',4 DDT & $0,5-10$ & 0,998 & 0,208 & 0,624 & $93,4 \pm 4,4$ & 6,39 & 6,06 \\
\hline 4,4'-DDE & $0,5-10$ & 0,998 & 0,237 & 0,711 & $99,7 \pm 4,2$ & 9,41 & 9,34 \\
\hline 4',4 DDD & $0,5-10$ & 0,996 & 0,206 & 0,618 & $97,5 \pm 3,9$ & 7,68 & 7,83 \\
\hline 2',4 DDT & $0,5-10$ & 0,997 & 0,215 & 0,645 & $97,1+4,5$ & 6,12 & 5,35 \\
\hline HEP & $0,5-10$ & 0,997 & 0,217 & 0,651 & $93,9 \pm 2,9$ & 6,86 & 6,44 \\
\hline \multicolumn{8}{|l|}{$\begin{array}{l}\text { Poliklorlu } \\
\text { Bifeniller }\end{array}$} \\
\hline РCB28 & $0,1-10$ & 0,998 & 0,194 & 0,582 & $96,3 \pm 1,3$ & 14,59 & 12,33 \\
\hline PCB52 & $0,1-10$ & 0,997 & 0,181 & 0,543 & $95,6 \pm 2,8$ & 10,57 & 9,48 \\
\hline PCB101 & $0,1-10$ & 0,996 & 0,227 & 0,681 & $95,6 \pm 1,2$ & 10,79 & 10,46 \\
\hline PCB118 & $0,1-10$ & 0,998 & 0,193 & 0,579 & $97,3 \pm 2,4$ & 9,52 & 9,23 \\
\hline PCB138 & $0,1-10$ & 0,997 & 0,214 & 0,642 & $98,6 \pm 3,1$ & 10,44 & 9,74 \\
\hline PCB 153 & $0,1-10$ & 0,997 & 0,216 & 0,648 & $98,7 \pm 3,6$ & 8,61 & 8,14 \\
\hline PCB180 & $0,1-10$ & 0,996 & 0,273 & 0,819 & $97,8 \pm 4,8$ & 10,02 & 9,40 \\
\hline \multicolumn{8}{|c|}{$\begin{array}{l}\text { Polibromlu } \\
\text { Difenil Eterler }\end{array}$} \\
\hline PBDE17 & $0,1-10$ & 0,996 & 0,124 & 0,372 & $98,9 \pm 2,5$ & 14,59 & 12,33 \\
\hline PBDE47 & $0,1-10$ & 0,997 & 0,169 & 0,507 & $97,4 \pm 2,2$ & 10,57 & 9,48 \\
\hline PBDE66 & $0,1-10$ & 0,997 & 0,214 & 0,642 & $96,7 \pm 3,3$ & 10,79 & 10,46 \\
\hline PBDE100 & $0,1-10$ & 0,998 & 0,196 & 0,588 & $98,4 \pm 3,7$ & 9,52 & 9,23 \\
\hline PBDE153 & $0,1-10$ & 0,997 & 0,152 & 0,456 & $92,3+4,8$ & 10,02 & 9,40 \\
\hline PBDE183 & $0,1-10$ & 0,995 & 0,157 & 0,471 & $93,4+4,4$ & 10,44 & 9,74 \\
\hline
\end{tabular}

\section{Sonuç}

Yapılan bu çalışmada Eğirdir Gölü’nün 48 farklı noktasından seçilen ve mevsimsel olarak toplanan 192 su örneği organik klorlu pestisit, polibromlu difenil eter, poliklorlu bifenil varlığı yönünden GC/MS ile analiz edilmiş ve örneklerin hepsinde bu bileşiklerin miktarları LOD değerinin altında bulunmuştur. $\mathrm{Bu}$ durum, Eğirdir gölü ve çevresinin kalıcı organik kirleticiler yönünden temiz olduğuna işaret etmektedir. Ancak, bu ve benzeri bileşiklerin çok az miktarlarının bile tehlike arz ettiği düşünüldüğünde tarama çalışmaların sıklıkla yapılması gerekliliği önem arz etmektedir. Bununla birlikte, bu bileşiklerin biyoakümülasyon özellikleri göz önünde bulundurulduğunda bu çalışmaların bentik canlılarda gerçekleştirilecek olan çalışmalarla da desteklenmesi önerilmektedir. 


\section{Yazarların Katkısı}

Makale için hipotezin oluşturulması, sonuçların yorumlanarak makalenin yazımında Dr. Öğr. Üyesi Ulaş ACARÖZ, numunelerin toplanması ve analize gönderilmesinde Veteriner Hekim Serkan KARATEKELİ ve Prof. Dr. Sinan İNCE, analizlerin yapılmasında Dr. Öğr. Üyesi Özgür KUZUKIRAN ve Prof. Dr. Ayhan FILLAZİ katkı sağlamıştır.

\section{Çıkar Çatışması Beyanı}

Yazarlar arasında herhangi bir çıkar çatışması bulunmamaktadır.

\section{Araştırma ve Yayın Etiği Beyanı}

Yapılan çalışmada araştırma ve yayın etiğine uyulmuştur.

\section{Kaynaklar}

[1] Paumo H.K., Das R., Bhaumik M., Maity A. 2020. Visible-Light-Responsive Nanostructured Materials for Photocatalytic Degradation of Persistent Organic Pollutants in Water. In Green Methods for Wastewater Treatment. Springer, Cham, 1-29.

[2] Milun V., Lušić J., Despalatović M. 2016. Polychlorinated biphenyls, organochlorine pesticides and trace metals in cultured and harvested bivalves from the eastern Adriatic coast (Croatia). Chemosphere, 153: 18-27.

[3] Gray J.S. 2002. Biomagnification in marine systems: the perspective of an ecologist. Marine Pollution Bulletin, 45 (1-12): 46-52.

[4] Jones K.C., De Voogt P. 1999. Persistent organic pollutants (POPs): state of the science. Environmental Pollution, 100 (1-3): 209-221.

[5] Acaroz U., Arslan-Acaroz D., Ince S. 2019. A Wide Perspective on Nutrients in Beverages in Nutrients in Beverages Volume 12: The Science of Beverages. Edited by Grumezescu A.M. and Holban A.M., Academic Press, 1-39.

[6] Verhaert V., Newmark N., D’Hollander W., Covaci A., Vlok W., Wepener V., Addo-Bediako A., Jooste A., Teuchies J., Blust R., Bervoets L. 2017. Persistent organic pollutants in the Olifants River Basin, South Africa: bioaccumulation and trophic transfer through a subtropical aquatic food web. Sci Total Environ., 586:792-806.

[7] Naushad M. 2014. Surfactant assisted nano-composite cation exchanger: Development, characterization and applications for the removal of toxic $\mathrm{Pb} 2+$ from aqueous medium. Chemical Engineering Journal, 235: 100-108.

[8] Google maps. Eğirdir Gölü. https://www.google.com/maps/place/E\%C4\%9Firdir+G\%C3\%B61\%C3\%BC/@38.0611707,30. 5760993,10z, (Erişim Tarihi: 16.01.2020).

[9] Magnusson B., Ornemark U. 2014. Eurachem Guide: the Fitness for Purpose of Analytical Methods - A Laboratory Guide to Method Validation and Related Topics (second ed.), ISSN: 978-91-87461-59-0.

[10] Kuzukiran O., Yurdakok-Dikmen B., Totan F.E., Celik C., Orhan E.C., Bilir E.K., Kara E., Filazi A. 2016. Analytical method development and validation for some persistent organic pollutants in water and sediments by gas chromatography mass spectrometry. International Journal of Environmental Research, 10 (3): 401-410.

[11] Kuzukiran O., Yurdakok-Dikmen B., Sevin S., Sireli U.T., Iplikcioglu-Cil G., Filazi A. 2018. Determination of selected endocrine disruptors in organic, free-range, and battery- produced hen eggs and risk assessment. Environmental Science and Pollution Research, 25 (35): 35376-35386.

[12] Kuzukiran Ö., Filazi A., Arslan P., Yurdakök-Dikmen B., Tavşanoğlu Ü.N.Y. 2019. Kızılırmak Nehri'nden Alınan Su ve Sediment Örneklerinde Kalıcı Organik Kirleticilerin Tespiti. Kocatepe Veteriner Dergisi, 12 (4): 430-438. 
[13] Ünal E.D. 2010. Kuzey Doğu Akdeniz'de (Mersin Körfezi) deniz suyu, sediman ve biyotada organik klorlu pestisit kirlilik düzeyinin araştırılması. Doktora Tezi, Mersin Üniversitesi, Fen Bilimleri Enstitüsü, Mersin.

[14] Malik A., Ojha P., Singh K.P. 2009. Levels and distribution of persistent organochlorine pesticide residues in water and sediments of Gomti River (India)-a tributary of the Ganges River. Environmental Monitoring and Assessment, 148 (1-4): 421-435.

[15] Han D., Currell M.J. 2017. Persistent organic pollutants in China's surface water systems. Science of the Total Environment, 580: 602-625. 